\title{
Values in times of austerity: A cross-national and cross-generational analysis
}

\author{
Jan Germen Janmaat \\ g.janmaat@ioe.ac.uk \\ Institute of Education, University College London
}

\begin{abstract}
It is common knowledge that in times of recession people lose confidence in the government and in other state institutions. Political scientists have pointed out that a loss of faith in a particular government or parliament does not necessarily amount to an erosion of civic culture as the cultural foundation of liberal democracy is broader. However, the recent recession has been unusually severe and long-lasting and some countries have only just started to climb out of it. It is an open question whether civic culture is so resilient that it can even weather exceptionally serious economic crises such as the recent one. As often happens in times of crisis, young people have been most affected by the recent crisis, and one may thus expect this age group to show the steepest drops in civic values. The current article examined the impact of the recession on the civic values of different generations across a selection of European and western states. Analyses of both short and long-term trends based on European Social Survey (ESS) and World Values Survey (WVS) data showed that social trust, tolerance, active civic participation and post-materialism values, as civic culture indicators, are not susceptible to economic downturns, confirming the idea that civic values need to be distinguished from political trust. Correlational analysis provided additional support for this finding as it showed no links between changes in civic culture indicators and changes in economic performance. However, civic dispositions were found to be related to overall levels of economic prosperity and performance, indicating that such dispositions are not wholly immune to material
\end{abstract}


conditions. This led us to surmise that civic culture is more susceptible to enduring processes affecting people's life chances and well-being than to fleeting phenomena such as economic crises.

\section{Keywords}

Economic crisis

Civic values

Young people

Comparative analysis

Trend analysis

ESS / WVS

\section{Introduction}

It is common knowledge that in times of recession people lose confidence in political institutions. Government and parliament are perceived as incapable of providing the necessary social protection and reviving the economy. People express their discontent by taking to the street to protest against austerity measures or tax increases. The introductory article to this special issue has documented these trends for the 2008 crisis, which hit Europe very badly. It showed that political trust has declined markedly in most countries, and particularly so in the countries most affected by the crisis. These same countries have also seen a surge in protest activities including demonstrations and occupations. 
The question this raises is whether public discontent with politics in times of crisis spills over into civic values more broadly. Are people not only losing faith in political institutions but also withdrawing their support for the values and attitudes that are often associated with liberal democracies, such as tolerance, human rights, freedom of speech and social trust? If this is the case, economic crises like the recent one can pose a real danger for the stability and survival of democracy.

On the one hand, there are indications that economic crises do have these wider effects. Thomassen (1990), for instance, notes that the stagflation of the 1970s was seen a major threat to the stability of western democracies in many popular accounts at the time. Others point to the propensity of xenophobia to rise in times of crisis, expressed politically as support for populist parties with anti-immigrant agendas and a propensity to scapegoat particular social or ethnic groups (Ibarra 2011). Academic support for the idea that economic downturns pose a threat to democracy comes from Inglehart and Welzel (2005). They maintain that in times of crisis people deem economic and physical security to be more important than lofty values such as democracy, human rights and social justice. In austere times they might therefore be less motivated to oppose political movements seeking to abolish democracy.

Others, on the other hand, have argued that a loss of confidence in the institutions of democracy does not necessarily amount to a declining legitimacy of democracy and an erosion of civic values (Finkel et al 1989; Klingemann 1999). They note that since the 1960s a new group of citizens emerged combining a sceptical attitude towards authority and power hierarchies with ardent support for human rights and democracy. If political distrust is a manifestation of this sceptical attitude, then declining political trust can easily go together with stable or rising support for civic values and democracy as system of government. Indeed, critical citizens are praised by some for their inclination to hold politicians accountable and keep democratically elected governments responsive (Gamson 1968; Kymlicka 2002). According to Lipset (1959), 
established democracies, even if they do not perform well in times of crisis, usually survive economic storms by maintaining high levels of public legitimacy. In his view, only when both performance and legitimacy have declined dramatically is democracy seriously at risk.

However, the recent recession has been unusually severe and long-lasting for many countries (Balcerowicz et al. 2013), and some countries are still experiencing economic contraction. Although the United Kingdom has now climbed out of the recession, only 55 months after the start of the crisis did its economy attain pre-crisis levels (see Figure 1), and real wages are not expected to reach 2008 levels before 2018. The figure shows that the current crisis is not as deep as the one in the 1930s, but the recovery has been much slower. It is an open question whether support for civic values is so resilient that it can even weather exceptionally serious economic crises such as the most recent one.

Moreover, crises do not affect everyone equally. The current crisis is no different from previous ones in that young people take the brunt. Many observers have expressed concerns about the socio-political consequences of the disproportionate impact of the crisis on young people (e.g. Pilkington and Pollock 2015; Williamson 2014). Williamson (2014), for instance, speculates that young people's reaction can take any form, ranging from radicalization to concerted political mobilization within the bounds of the law.

There is however huge variation across states in the degree to which young people are affected, even among states hit hardest by crisis. Among the latter we find for instance states such as the Netherlands, Slovenia and Ireland with quite moderate young unemployment figures (hovering around 10 to 13 per cent) and states where these figures exceed 40 per cent (Greece, Italy, Portugal and Spain) (Eurostat 2013). As the young have suffered disproportionately in the crisis one would expect this age group to show the steepest falls in support for civic values and democracy. If these outcomes have indeed been affected by the recent crisis, the falls should 
be most pronounced in countries where young people have been hit particularly hard. Previous research has shown that young people in the countries most affected by the crisis (i.e. Southern Europe) have certainly not become more apathetic or alienated as their levels of protest have soured (Simsa 2015). This might be interpreted as a preliminary positive sign that they have not abandoned faith in legitimate democratic means of political mobilization.

Figure 1: Crisis and recovery in the United Kingdom.

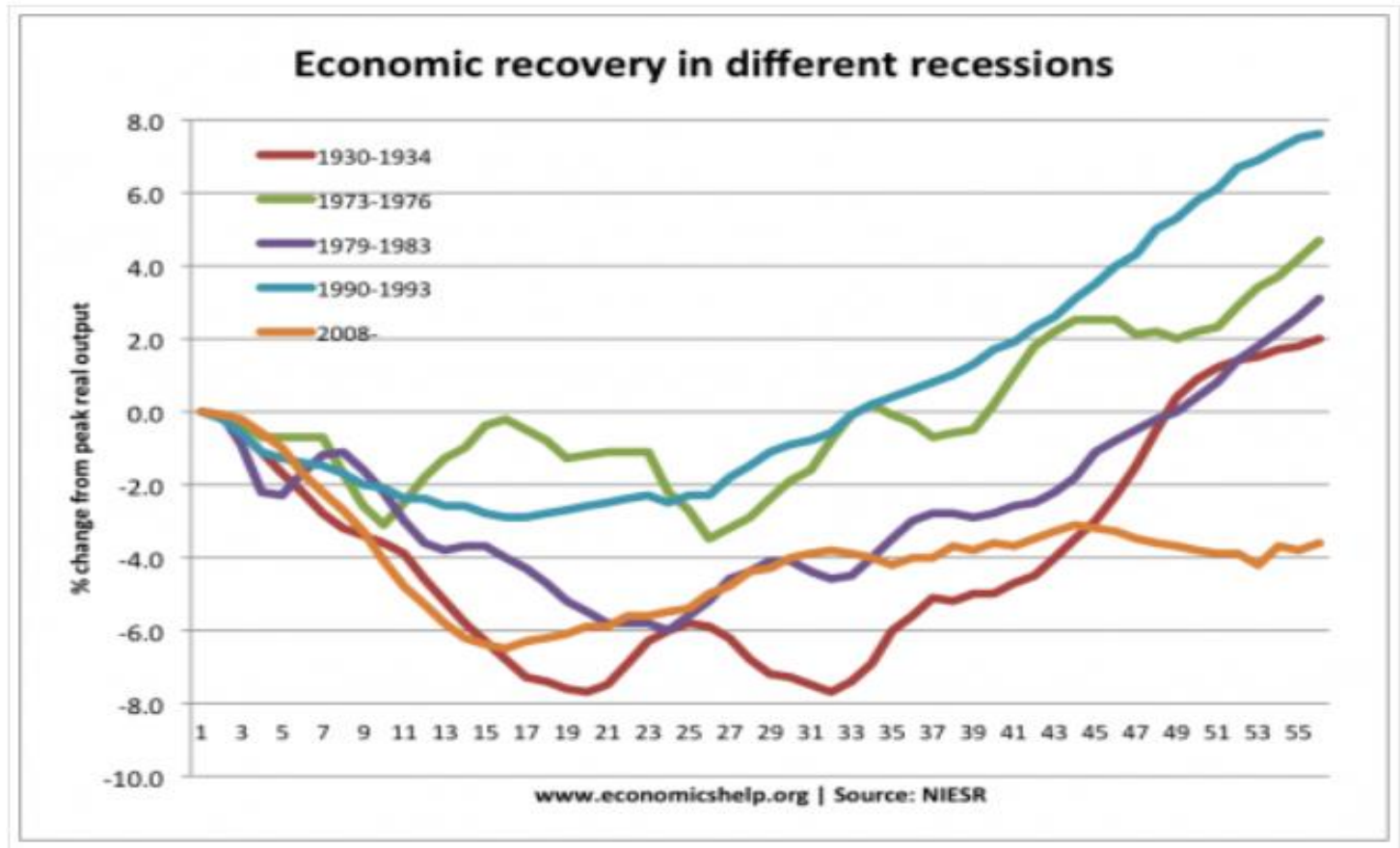

The current article will explore the resilience of civic values by analysing trends across birth cohorts in a select group of countries and by relating young people's civic attitudes to indices of economic performance. Use is made of survey data from the European Social Survey (ESS), rounds 2002 to 2012, to assess short term trends in civic outcomes. As this survey runs every two years, it allows us to establish more precisely when rises or falls in these outcomes occur. 
Data from the World Values Survey (WVS), years 1981 to 2010-2013, are used to explore developments over the longer term, enabling us to see how the 1980-2000 birth cohort in 20102013 compares to older cohorts at some point in the past when they were of the same age as the 1980-2000 cohort. It also gives us some clues to assess whether the most recent crisis has had more profound effects on civic outcomes than earlier crises, such as those of the early 1980s and 1990s. ESS includes people aged 15 and older (no upper limit), while WVS sampled people between ages 18 and 85 .

The trends will be presented by birth cohort (1880-1944; 1945-1959; 1960-1979; 1980-2000) in individual countries. These cohorts correspond closely to familiar generational characterizations, such as the Traditionalists, the Baby-Boomers, Generation $\mathrm{X}$ and the Millenials. Because of this presentation by cohort a word of caution is warranted regarding the number of respondents in each of the groups. Although both surveys are nationally representative with country samples for each round ranging between 990 and 4000 respondents for the WVS and between 1600 and 3000 respondents for the ESS, numbers drop when splitups are made by birth cohort. This is especially a problem in Round 1999-2004 of the WVS for the youngest birth cohort (1980-2000) as sample sizes fall below 100 respondents for this group in a number of countries.

${ }^{1}$ In all the other groups the sample is larger than 100 however. For the ESS the problem is less acute as each birth cohort is represented by at least 200 respondents in each country in each of the rounds. Because of the poor representation of the youngest cohort in the aforementioned WVS round, we will be cautious in making bold statements about long-term trends for this group.

We will explore these trends for only a limited set of countries, namely the United Kingdom, the United States, Spain, Germany, Sweden and Poland, so as to not overwhelm the reader with 
data. We selected these countries for three reasons. First, each of these states can be said to be a typical representative of a certain welfare regime (e.g. Esping Andersen 1990). A country's welfare regime is relevant as it reflects the degree of social protection offered to citizens who become unemployed during a recession. In the United Kingdom and the United States, countries with a liberal welfare regime, individuals are more exposed to the vagaries of the market economy than in countries with a social-democratic regime, such as Sweden, where the unemployed, irrespective of their employment history, enjoy relatively lavish benefits (Esping Andersen 1990; Green and Janmaat 2011). In countries with a traditional regime, such as Spain, the family plays an important role in mitigating the social upheaval of market economy turbulences. In Germany, a country said to exhibit a conservative regime, benefits depend on employment history and last earned salary. Unemployment could thus have particularly dramatic consequences for those who have never worked before or who worked in low-paid jobs, as is the case for many young people. Poland represents a post-communist country with a welfare state blending features of both the conservative and liberal model (Staręga-Piasek et al. 2006), thus offering relatively little protection for young people who lose their jobs. As in Spain, the family can be expected to play an important role in absorbing the fall-out of the crisis. One could imagine that young people respond more extremely to economic shocks where the safety net is marginal. Consequently one might expect the most dramatic falls in civic values to have occurred in the United Kingdom and the United States, and to a lesser extent in Poland, Spain and Germany.

Secondly, the six countries were selected because they represent a range of fortunes with respect to the recent crisis. At the extremes of this range are Spain and Germany (see Table 1). While Spain experienced a dramatic contraction in its economy and a surge in youth unemployment from an already markedly high pre-crisis level, Germany was hardly affected by the crisis neither macro-economically nor specifically regarding youth unemployment. The 
other countries are located in the middle of the continuum with the United Kingdom being closer to the Spanish end and Sweden and Poland being more similar to Germany. The latter two countries are interesting as they show good macro-economic performance, in terms of change in GDP per capita from 2008 to 2012, in combination with rising youth unemployment, recording increases of 12.7 and 10.5 per cent, respectively, over the same period. This suggests that the economic crisis has had a different impact on different generations in these countries. Thus, if civic values were solely influenced by economic conditions, one would expect Spain to witness sharp falls in civic mindedness, Germany not to show any decline and Sweden and Poland to register diverging responses among different generations with young people showing the most salient declines.

The third reason is more pragmatic as it relates to the data available in the WVS. Spain, Sweden, Germany and the United States happen to be the only countries that have participated in all waves. We used the United States as a stand in for the United Kingdom in view of the absence of the latter in the last wave.

Table 1: Economic performance of selected countries during the crisis.

\begin{tabular}{|c|c|c|c|}
\hline & $\begin{array}{l}\text { Change in GDP per } \\
\text { capita 2008-2012 } \\
(\%)\end{array}$ & $\begin{array}{l}\text { Youth } \\
\text { unemployment rate } \\
\text { August } 2008\end{array}$ & $\begin{array}{l}\text { Change in youth } \\
\text { unemployment } \\
\text { August 2008- } \\
\text { August } 2012\end{array}$ \\
\hline Germany & 3.8 & 10.0 & -2.0 \\
\hline Poland & 12.5 & 16.2 & 10.5 \\
\hline
\end{tabular}




\begin{tabular}{|l|l|l|l|}
\hline Spain & -7.4 & 25.0 & 29.4 \\
\hline Sweden & 3.4 & 10.2 & 12.7 \\
\hline United Kingdom & -4.1 & 15.4 & 5.2 \\
\hline
\end{tabular}

Sources: Eurostat (2015) for youth unemployment; Balcerowicz et al. (2013) for GDP per capita.

The outcomes we focus on include social trust, tolerance, active civic participation and postmaterialist values. Most of these qualities have been identified as key components of civic culture by different authors (Almond and Verba 1963; Galston 1991; Putnam 1993; Inglehart and Welzel 2005). Although these scholars have different understandings of civic culture and consequently assign different characteristics to it, they are in agreement in seeing this culture as a sine qua non for democracy. In other words, even with all the proper institutions in place, a democracy will not function well and will not be durable if it is not supported by civically minded citizens. Thus, the relevance of the aforementioned qualities lies in sustaining the cultural foundation of democracy.

We start by examining trends in civic outcomes across cohorts for the select group of countries. ${ }^{2}$ The second section we correlate these outcomes with cumulated changes in GDP per capita and youth unemployment levels.

\section{Trends by birth cohort and age group}

\section{Social trust}


We begin our survey of trends with social trust, which we understand as trust in people in general, including strangers. In contrast to political trust, which is volatile and dependent on the degree of identification with the parties in power, social trust is fairly stable and is mostly a reflection of one's own social position and that of one's parents (Newton 1999). Unlike political trust, it is formed early in life through parental upbringing (Uslaner 2002). Social trust has been associated with a variety of societal benefits including economic growth (Knack and Keefer 1997), better government (Putnam 2000), and well-being and happiness (Wilkinson and Pickett 2009). For this reason it is often used as a key indicator of overall social cohesion (e.g. Green and Janmaat 2011). Many scholars have also stressed its vital importance for democracy (e.g. Ostrom 1990; Fukuyama 1995). Social trust enables cooperation between people of different backgrounds and their interest organizations, including political parties, unions and churches, which is a key characteristic of liberal democracy (Newton 1999). Without it democracy is likely to disintegrate as a result of escalating conflicts between different social groups. ESS tapped social trust with the item 'Generally speaking, would you say that most people can be trusted, or that you can't be too careful in dealing with people?' Response categories represent a scale ranging from $0=$ 'you can't be too careful' to $10=$ 'most people can be trusted'. WVS used the same wording but offered respondents no more than a binary choice between these two options.

Figure 2: Short term trends in social trust by cohort in selected European countries. 

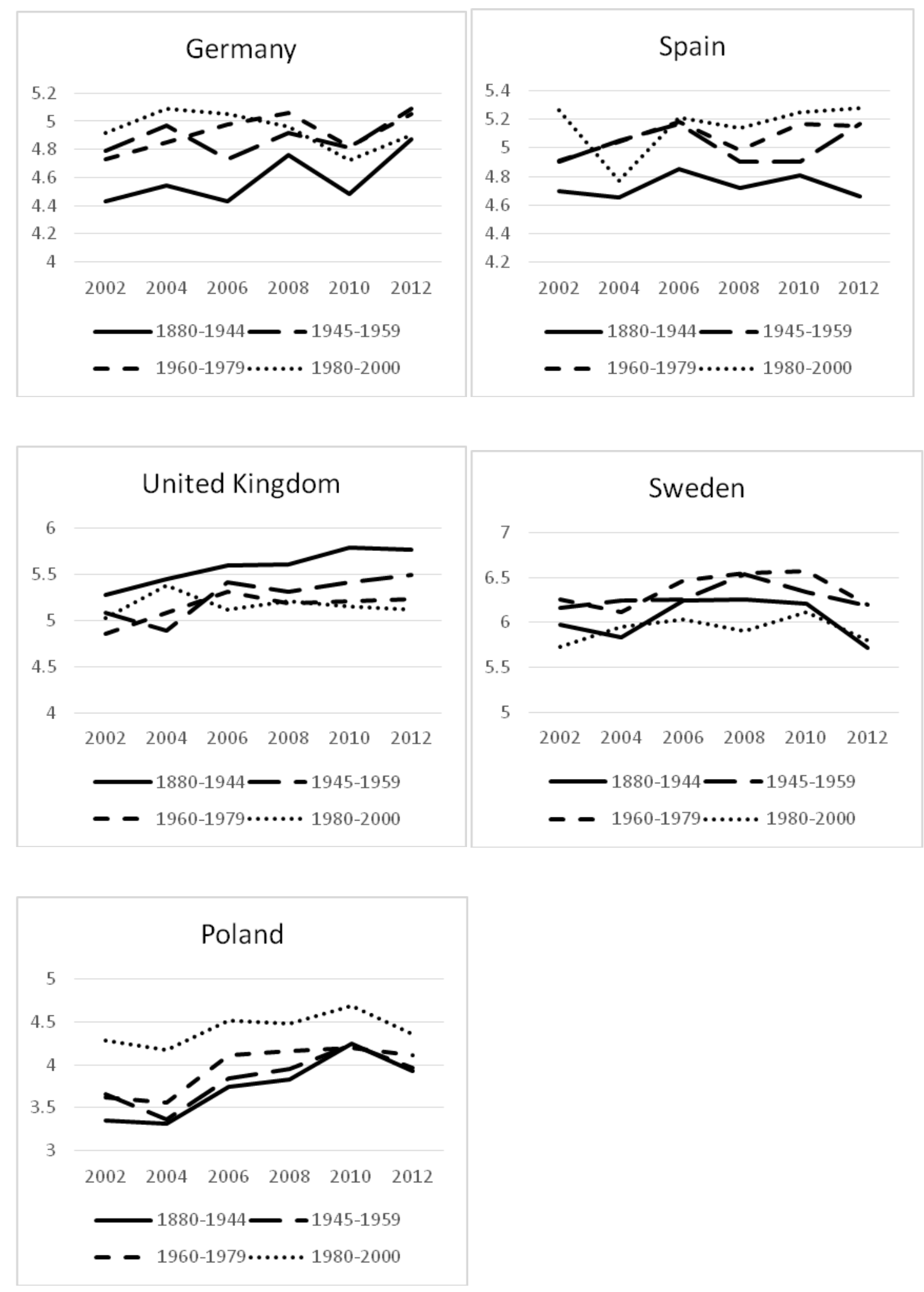

Source: ESS.

Note: The figure shows mean levels of trust on an 11 point scale ranging between $0=$ 'you can't be too careful' and 10='most people can be trusted'. 
Looking at how social trust has developed from the early 2000s amongst four birth cohorts in selected European states, we cannot see any clear cross-national patterns (see Figure 2). Trends appear to be country-specific, with trust rising steeply amongst all cohorts in Germany from 2010 and declining amongst all cohorts in Poland and Sweden. There does not seem to be a connection with the economic crisis as trust has not fallen in countries hit hardest by the crisis (Spain) or amongst cohorts most affected by it, such as young people. In fact, in a country like Spain with a youth unemployment of over 50 per cent in August 2013 (Eurostat 2013) the youngest cohort shows both the highest level of trust of all cohorts and a rise in trust since the onset of the crisis. In the United Kingdom by contrast trust is lowest among the youngest generation. Since the onset of the crisis, the different generations appear to have drifted apart with the old becoming more and the young becoming less trusting. Interestingly this diverging pattern shows up in the United Kingdom and not in Sweden and Poland, where we would have expected it given the distinct combination of good overall economic performance with rising hardship for young people that characterizes these countries. Although the trends in the United Kingdom are not dramatic in absolute terms (as the observed changes are only minor on a scale from 0 to 10), they do suggest that social trust can change later in life due to changing circumstances. Hence, it would not be correct to claim that social trust takes on a definite form in early childhood.

Figure 3: Long-term trends in social trust by birth cohort in selected western countries. 

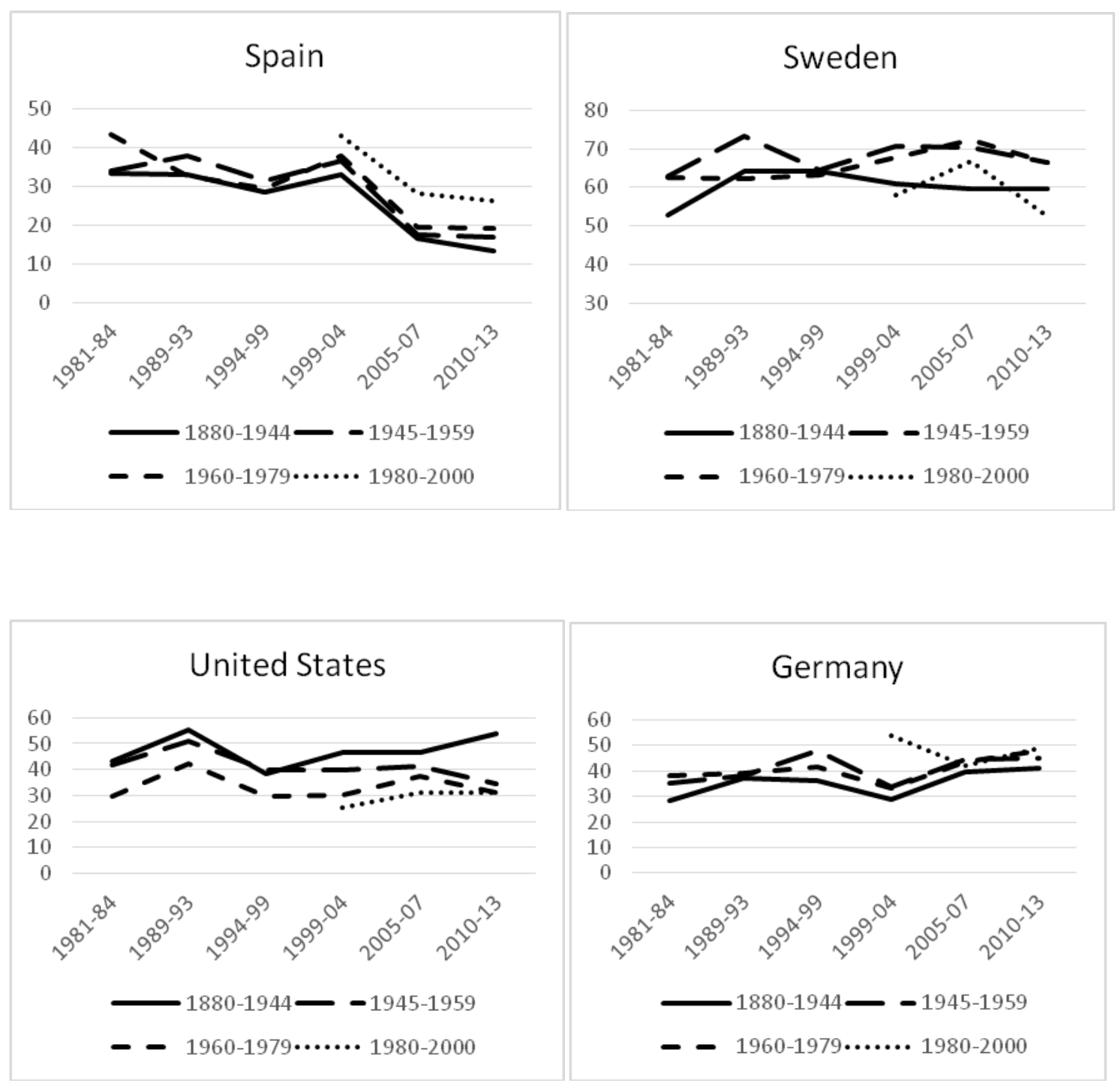

Source: WVS.

Note: The figure shows the percentage saying that most people can be trusted.

Country-specific trends also predominate when we look at long-term trends (see Figure 3). While social trust has gone up in Germany, declining trends can be observed in Spain over the last three decades. These trends are visible among all generations, albeit with some fluctuations. It is tempting to draw a link with the diverging economic fortunes of the two countries since the onset of the crisis, but if we take a closer look at the trends in Spain we see that the fall in trust was most pronounced from the late 1990s to the mid-2000s when the country was experiencing a period of sustained economic growth. Thus, as was the case for the 
short term trends, there does not seem to be a connection with periods of economic contraction. Spain and Germany do have in common that the younger generations are more trusting than the older ones. In this they contrast markedly with Sweden and the United States where the youngest cohort shows the lowest level of trust towards the end of the time series. Another difference is that in the latter two countries trends do differ by generation: while trust has gone up in the oldest cohort in both countries, it stabilized (United States) or declined sharply (Sweden) in the youngest cohort. So looking over a longer period of time, we do see the expected trend in Sweden of generations drifting apart in levels of social trust.

\section{Tolerance}

Tolerating people who differ from oneself in important ways is generally considered to be a key liberal democratic virtue (Putnam 1993). If there is no respect for people of different backgrounds and with different interest, it is difficult to see how conflicts can be resolved in a peaceful democratic way. However, tolerance is also seen as an attitude that is quite susceptible to economic crises. Under conditions of scarcity and increasing competition for jobs, people often become more exclusionary and hostile towards out-groups such as immigrants, to the point of blaming them for all the problems in society including rising unemployment among the native population (van Beek and Vnuk-Lipinski 2011). Indeed, it appears to be rising antiimmigrant sentiment that is driving the current electoral successes of populist parties (Caviedes 2010; Downs 2012). In ESS we selected the item 'Is [country] made a worse or a better place to live by people coming to live here from other countries?' as a measure of ethnic tolerance. The answer categories represent an 11 point scale ranging between $0=$ 'worse place to live' to $10=$ 'better place to live'. In WVS we used the question asking respondents to mention groups they would not like to have as neighbours $(0=$ not mentioned; $1=$ mentioned $)$. We selected the group 'immigrants/foreign workers' and used the percentage not mentioning this group as an 
indicator of ethnic tolerance. Because of these different items the comparisons between short and long-term trends need to be read with caution.

Figure 4: Short term trends in ethnic tolerance by birth cohort in selected European countries.
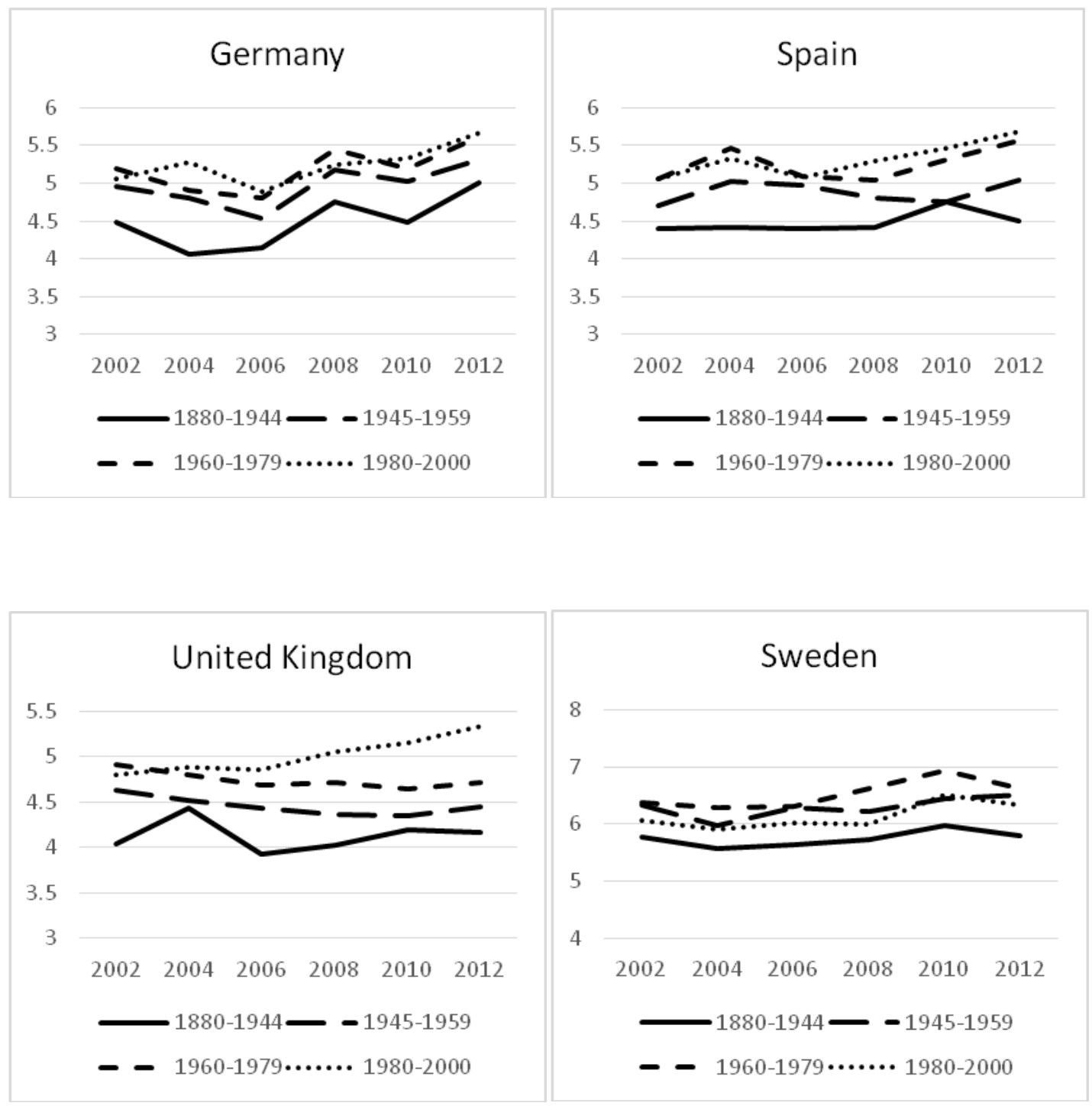


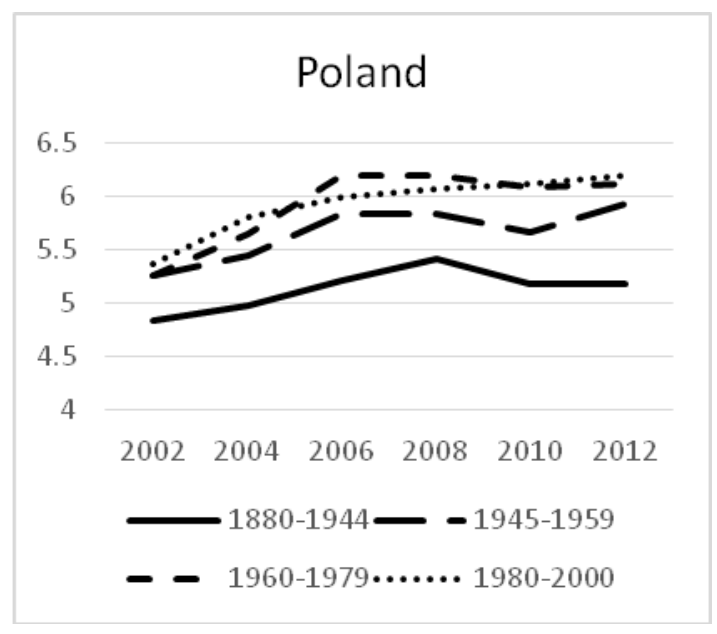

Source: ESS.

Note: The figure shows mean levels of ethnic tolerance. The means are based on the 11 point scale referred to above.

Contrary to expectation people appear not to have become more negative in their views on immigrants since the onset of the crisis in 2008 (Figure 4). In fact tolerant attitudes towards immigrants have risen among all birth cohorts in four of the five selected countries, including crisis-afflicted Spain. Only in Poland do we see a levelling off of tolerance from 2008 onwards after a steady rise from the early 2000 s. Interestingly we see a diverging pattern in this country but not the one we would have expected: while the youngest generation becomes more positive, the oldest generation grows more negative in their views on immigrants. In sum, the regularity that anti-immigrant sentiment thrives in periods of recession is not borne out at all by these trends. It is further revealing that the youngest cohort is the most tolerant and shows one of the highest growth figures in the United Kingdom, Spain, Germany and Poland. Thus, the generation that suffered most from the economic crisis is not only most welcoming in their 
attitudes towards immigrants but is also becoming increasingly tolerant, again defying the logic that scarcity breeds hostility.

Figure 5: Long-term trends in ethnic tolerance by birth cohort in selected western countries.
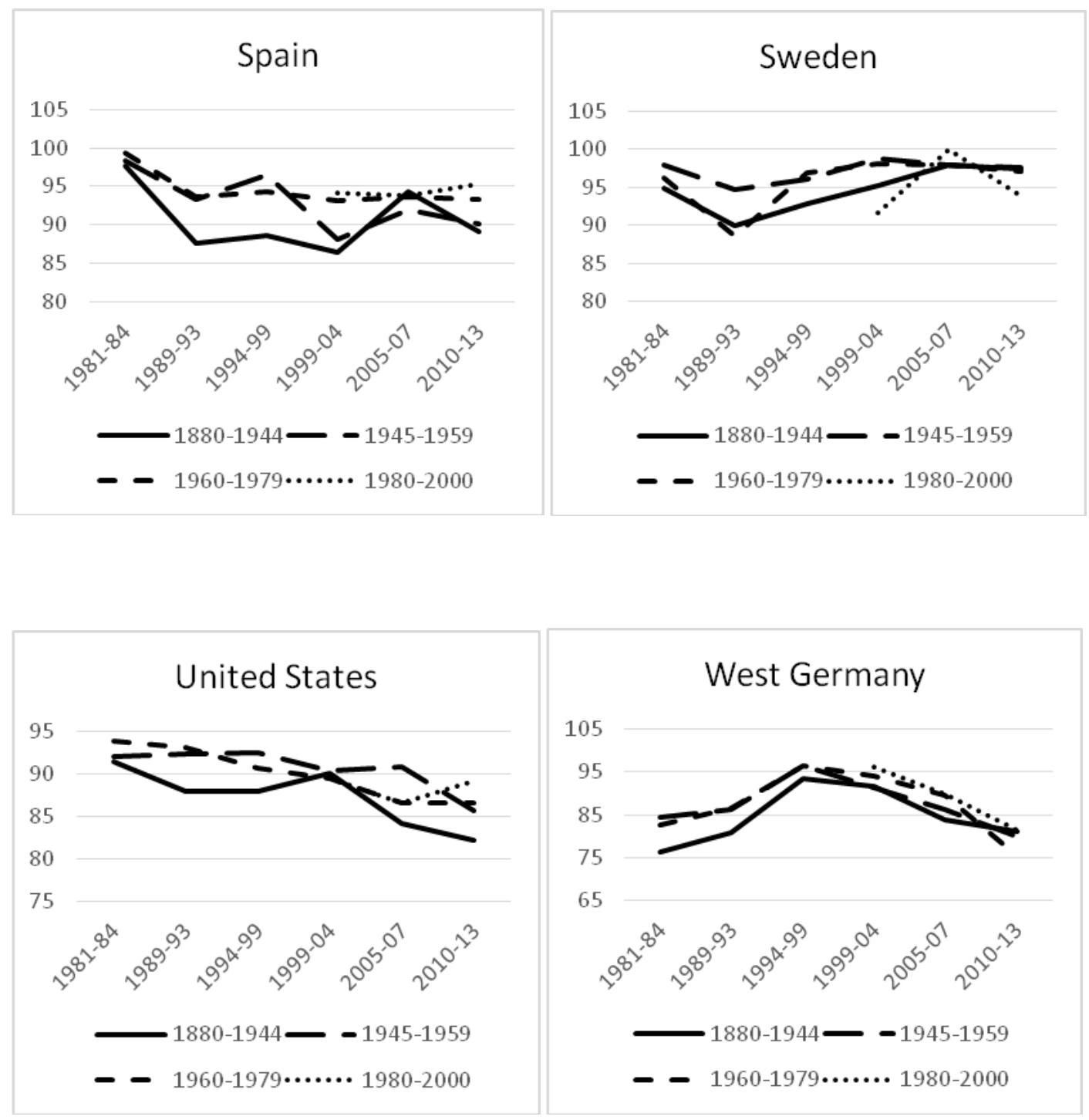

Source: WVS.

Note: the figure shows the percentage not mentioning immigrants/foreign workers as unwanted neighbours. 
The long-term trends do not tally with the short term ones. Instead of a rise in tolerance we see a downward trend in the United States and in Germany from the end of the 1990s to the present (Figure 5). In Sweden tolerance has risen until the mid-2000s ${ }^{3}$ after which point it declined, particularly amongst the young, mimicking the long-term trend in social trust. In Spain the trend lines are different again with tolerance reaching an all-time low at the end of the 1990s and showing a slight recovery since then. In this country the youngest generation has the highest level of tolerance and it is the only group showing an increase in tolerance from the mid-2000s. In short, country-specific trends predominate when looking at tolerance in the longer term. The link with economic scarcity is as good as non-existent as the group and the country that have suffered most from the crisis (i.e. the young in Spain) show an increase in tolerance. By contrast, tolerance has declined markedly amongst all generations in Germany, which has hardly been touched by the crisis Finally, it needs to be noted that the contrasting results on the ESS (short term) and WVS (long term) measures of tolerance are a sobering reminder that similar patterns cannot be guaranteed when looking at different items that seemingly measure the same latent construct.

\section{Active civic participation}

Civic associations are seen as a key feature of civic culture in many classic accounts of this phenomenon (e.g. de Tocqueville 1969; Almond and Verba 1963). They are considered to be crucial for the consolidation of democracy, not only because they socialize individual members in democratic qualities and dispositions such as trust, tolerance, moderation, cooperation and public spiritedness, but also because they function as a check on state power and provide channels of coordinated interest articulation which are vital for politicians to keep in touch with society (Putnam 1993; Fox 2000; Ishkanian 2007). In other words, they discipline their 
members internally and policy-makers externally. Following Hoskins et al. (2006: 10) we understand active civic participation as 'Participation in civil society, community and/or political life, characterized by mutual respect and non-violence and in accordance with human rights and democracy'.

To assess short term trends in this outcome we relied on the following ESS question: 'There are different ways of trying to improve things in [country] or help prevent things from going wrong. During the last twelve months, have you done any of the following?' (1) 'worked in a political party or action group'; (2) 'worked in another organisation or association'. The question did not give other options. We developed a measure of civic participation by combining the responses to these two items. The measure has two values: 0 - not worked in any of these organizations; 1 - worked in one or more of these organizations. An equivalent measure could not be constructed for the long-term trends as the WVS asked about active civic participation in a different way. To match the ESS-based measure as closely as possible we selected the question asking respondents whether they were a passive or active member of the following organizations: church, union, political party, environmental organization, professional organization, humanitarian or charitable organization. We used this question to create a long-term measure of active civic participation with two values (analogous to the short term measure): 0 - not an active member in any of these organizations; 1 - active member in one or more of these organizations. Again, because of the different wording, we are cautious in comparing the short with the long-term trends.

Figure 6: Short term trends in active civic participation in selected European countries. 

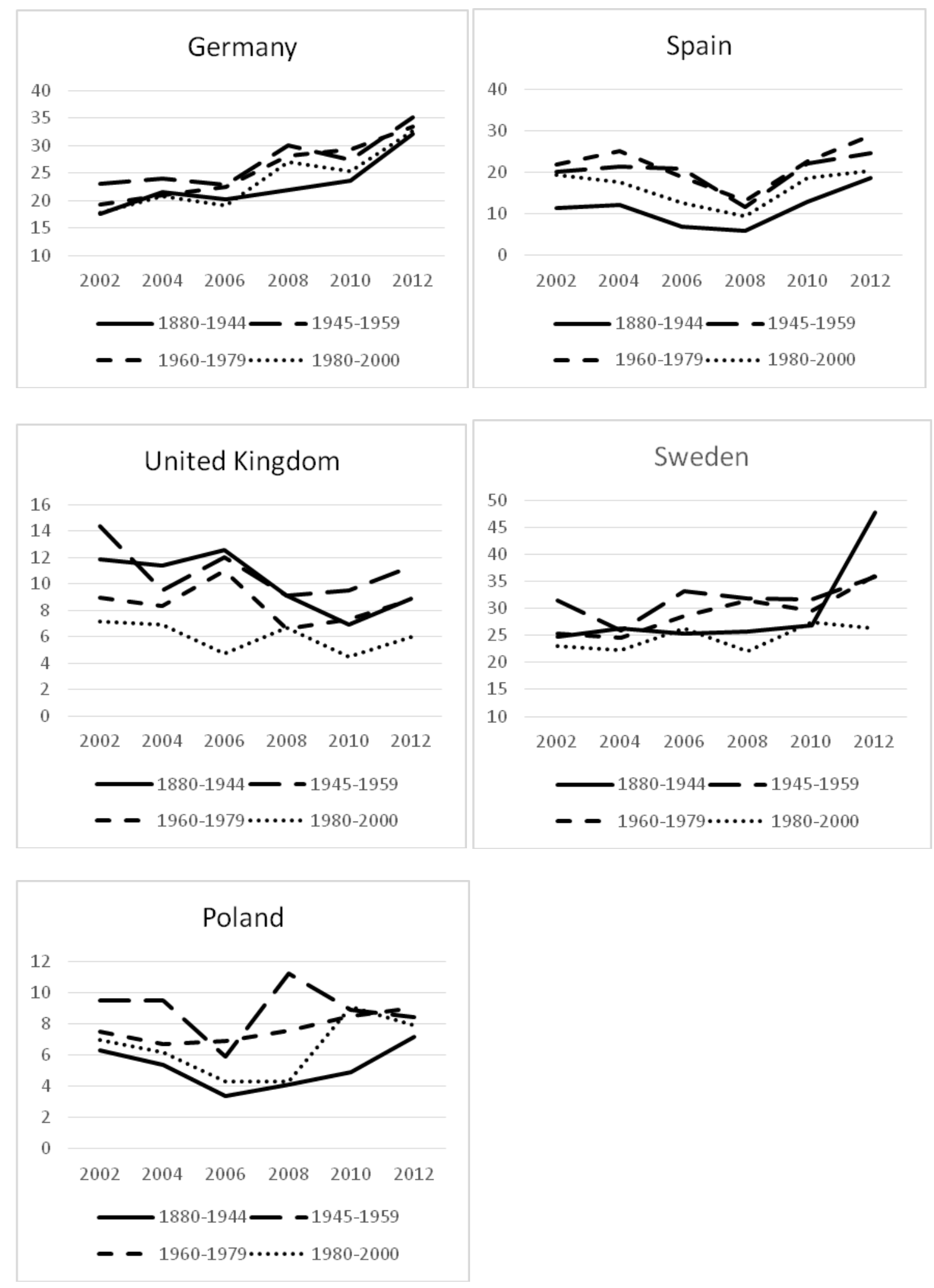

Source: ESS. 
Note: The figure shows the percentage saying they have worked for one or more organizations over the last twelve months.

In accordance with the trends in trust and tolerance, active involvement in civic associations appears not to have been affected by the economic crisis either (Figure 6). Although levels of involvement go down in Germany and the United Kingdom in the initial years of the crisis, this decline is more than compensated for by the rise from 2010 to 2012. In the other three countries we see participation actually rising from the beginning of the crisis in all generations, with the exception of the baby boom cohort in Poland. Once again, country-unique trends predominate. While Germany shows a marked rise in active participation among all cohorts over the whole ten-year period, the United Kingdom demonstrates a steady decline from 2002 to 2010 and a small recovery thereafter. A remarkable V pattern can be observed in Spain, with participation declining spectacularly from 2004 to 2008 and rising equally miraculously thereafter. In Sweden, we see a diverging pattern in line with our expectation: while participation goes up in the older cohorts, and spectacularly so amongst the oldest group, it stabilizes amongst the youngest cohort. Remarkably, a converging trend can be observed in Poland, which obviously is not what we expected to find. Also in terms of levels of participation the differences between the countries are conspicuous. The United Kingdom and Poland, for instance, show permanently lower levels than Germany, Spain and Sweden for all cohorts. In the United Kingdom and in Sweden the youngest generation consistently has the lowest levels of participation while in Germany, Poland and Spain the oldest generation is least involved.

Figure 7: Long-term trends in active civic participation in Spain and West Germany. 


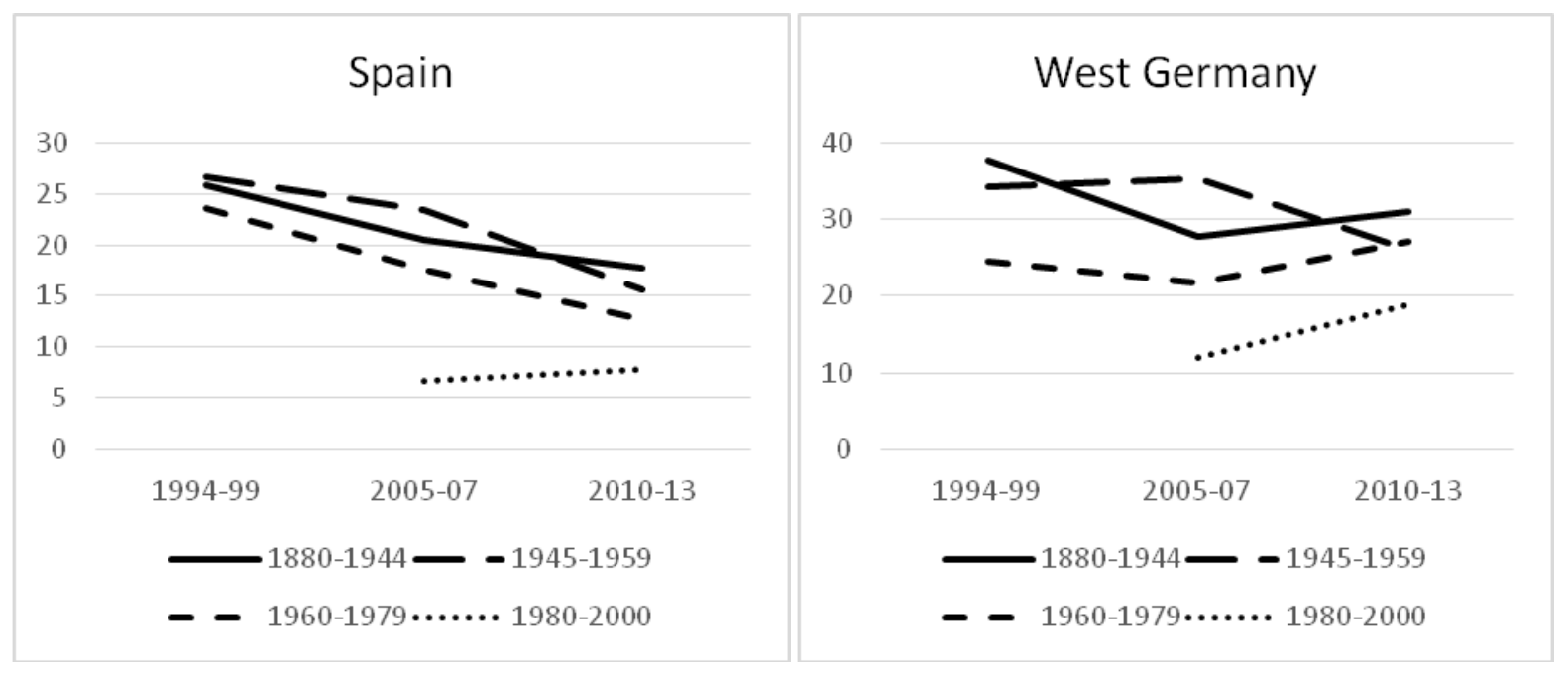

Source: WVS.

Note: The figure shows the percentage of respondents saying they have been an active member of one or more organizations.

Unfortunately the WVS data on long-term trends in active civic participation were only available for two countries and for three points in time. Looking at these trends, we see a steady decline among the older generations in Spain from the mid-1990s onwards (see Figure 7). In West Germany the trends are more unstable but there too participation seems to be declining among the older generations while rising among the younger ones. These developments are quite different from the short term trends, which obviously is likely to be related to the difference in measurement. As the measure of long-term trends is mainly based on involvement in traditional organizations, such as the church, unions and political parties, the decline in Spain may reflect a change in the kind of organizations people are willing to be actively involved in rather than a decline in active participation as such. This interpretation is supported by the fact that this decline is mainly due to falling levels of church involvement among the older cohorts. ${ }^{4}$ The trends in Spain could thus simply reflect secularization. This reading of the results is 
further backed up by the remarkably low levels of involvement of the youngest generation in both countries. Presumably, young people are the least enthusiastic about participating in traditional organizations and therefore most likely to participate in alternative ways (e.g. through online and social media activities). Whatever the explanation for these trends, they once again show no particular connection with the economic crisis: in Spain participation actually rises slightly amongst the youngest and oldest cohorts from the mid-2000s onwards while the same thing happens in Germany among three of the four cohorts.

\section{Post-materialism}

We conclude the review of trends with a discussion of developments in post-materialist values. As coined by Inglehart (1990), the term refers to notions of personal autonomy and selffulfilment. People with a post-materialist frame of mind not only value individual autonomy, they also cherish quality of life, having a say in matters, care for the environment and equal treatment of and respect for all social groups. People with materialist values, in contrast, value economic and physical security and care less about upholding civic norms such as participation, equal treatment and tolerance. The materialist-post-materialist values continuum bears resemblance to Maslow's (1943) pyramid of needs with materialist values referring to basic needs and post-materialist values representing the 'higher order' need of self-actualization. Inglehart and Welzel (2005: 192) considered post-materialist values to be a necessary ingredient of an effective democracy, i.e. a democracy in which formal civic and political rights are respected and lived up to by political elites in actual practice. In their view, the young tend to have stronger post-materialist values than older people since they grew up under safer and more prosperous conditions than older generations. They also claim that levels of postmaterialism go down in all age groups during times of economic contraction. We measured 
post-materialist values with the ready-made materialism-post-materialism index provided by the WVS. This index is based on the following items:

'If you had to choose among the following things, which are the two that seem the most desirable to you?'

- Maintaining order in the nation.

- Giving people more say in important political decisions.

- Fighting rising prices.

- Protecting freedom of speech.

While the first and the third option tap materialism, the second and the fourth ones capture post-materialist values. The index has three values: $1=$ materialist values; $2=$ mixed; $3=$ postmaterialist values. As no comparable items can be found in ESS we only present long-term trends.

Figure 8: Long-term trends in post-materialist values by birth cohort in selected western countries.

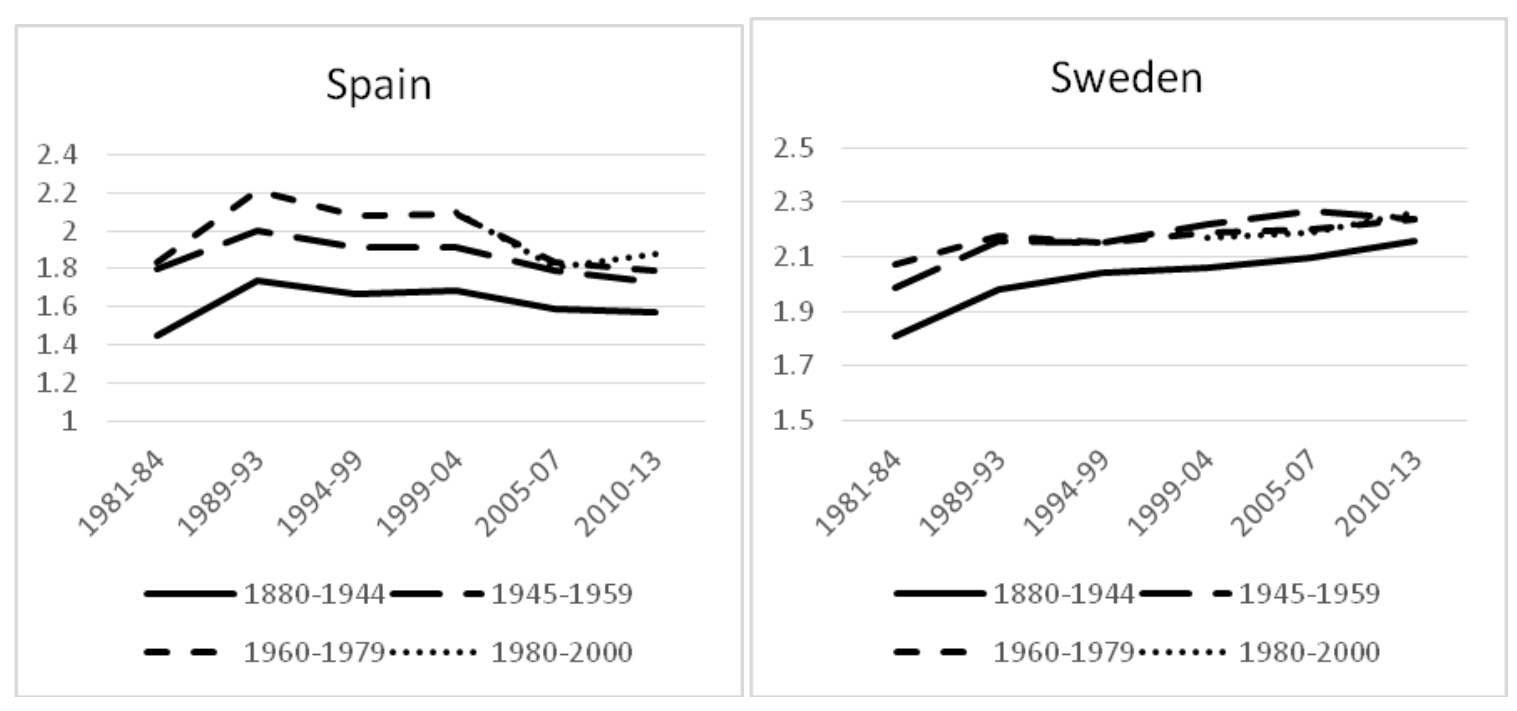




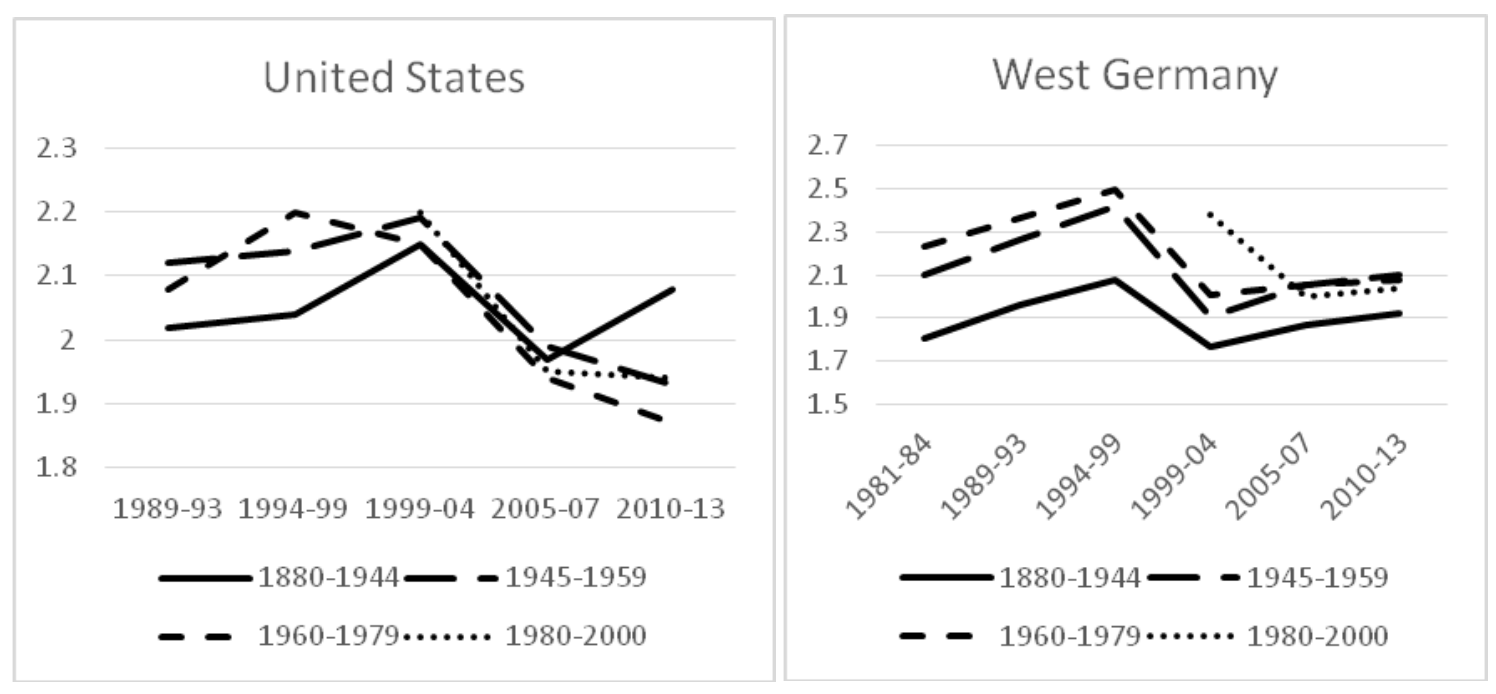

Source: WVS.

Note: The figure shows mean values on the materialism-post-materialism scale. This scale ranges between 1 (materialism) and 3 (post-materialism).

Trends in post-materialist values mimic those on the other three indicators of civic culture. Again we see no particular link with austerity as post-materialism was mostly stable or rose slightly from 2008 to 2013 in most cohorts in the four countries (see Figure 8). Remarkably, during this period it increased among the youngest generation in Spain while it decreased somewhat among the older ones in this country. Had the economic crisis had an effect on postmaterialism, as claimed by Inglehart and Welzel, we should have surely seen the reverse pattern. Once more the developments appear to be particular to each country. While Sweden witnesses a steady rise in post-materialism in all cohorts from the early 1980s onwards, Germany shows a fluctuating pattern with a dip in the early 2000s. Post-materialism peaked in Spain in the mid-1990s after which a small but steady decline set it. Interestingly we find quite contracting trends across birth cohorts in the United States. While post-materialism has risen 
amongst the oldest cohort, to such an extent that this cohort changes from the one with the lowest to the one with the highest level of post-materialism, it declines among the two youngest cohorts to an all-time low in 2013. Thus, in the United States we see a marked reversal of the regularity that younger generations are always more post-materialistically minded than older generations.

Summing up the trends on the four indicators of civic culture we cannot conclude that the economic crisis has had any particularly negative effect on the cultural foundations of democracy. Developments appeared to be quite country-specific suggesting that local conditions were more important in influencing civic values and behaviours than global processes. In a sense this is reassuring news. Apparently, civic culture is able to weather economic storms, even when they turn into hurricanes such as the most recent economic crisis. Yet, we also see trends that give us some cause for concern. The two youngest cohorts in the United States show quite a pronounced decline in post-materialism, which predates the 2008 crisis. This might indicate that other more enduring processes such as the rising cost of housing and education and ever higher levels of indebtedness have more of an impact on young people than the recent economic contraction.

\section{The link between economic performance and civic attitudes}

In this section we focus on the youngest birth cohort (1980-2000) and examine whether their civic values and behaviours are related to youth unemployment and GDP per capita as indices of economic performance. We correlate these indices with aggregate levels of civic dispositions amongst this cohort. These correlations are based on all the countries participating in the 2008 and 2012 rounds of ESS for which there are relevant data. We used the same indicators of civic 
dispositions as before. We also assessed relationships with aggregate levels of political trust to see whether civic dispositions are related in the same way to economic performance as political trust. $^{5}$ Unfortunately we could not use WVS data due insufficient European countries participating in the last wave. We therefore omitted post-materiast values. We first examine the links between levels of civic dispositions and economic performance and proceed by examining whether changes in these dispositions are related to changes in economic performance.

Table 2: The link between economic performance and young people's civic attitudes and behaviours.

Youth unemployment GDP pc PPP 2012-2013

rate (August 2012)

\begin{tabular}{|l|l|l|l|l|}
\hline & Pearson's r & $N$ & Pearson's r & $\boldsymbol{N}$ \\
\hline Political trust 2012 & $-0.63^{* * *}$ & 19 & $0.87^{* * *}$ & 22 \\
\hline Social trust 2012 & $-0.46^{* *}$ & 19 & $0.74 * * *$ & 22 \\
\hline Tolerance 2012 & -0.29 & 19 & $0.38^{*}$ & 22 \\
\hline Active civic participation 2012 & $-0.41^{*}$ & 19 & $0.70^{* * *}$ & 22 \\
\hline
\end{tabular}

$* p=0.1 ; * * p=0.05 ; * * * p=0.01$

Sources:

For youth unemployment, see Eurostat (2015).

For GDP pc PPP, see World Bank (2005). 
The review of trends in the first section of this article did not find much evidence of the recent economic crisis having affected civic culture. However, this review was based on a small selection of countries. Can any link with the economy be found when we expand the number of countries and run the correlations described above? Table 2 shows that civic culture is in fact not as immune to economic conditions as one might be led to believe based on the review of trends. We see that social trust, ethnic tolerance and active civic participation, as the three civic culture indicators, are linked in precisely the same way to the two indicators of economic performance as political trust: the lower a country's level of youth unemployment and the higher its level of prosperity, the higher the levels of civic culture among its younger citizens. Although these links are not as strong as those for political trust, judging from the coefficients and the significance levels, they nonetheless suggest that civic culture is at least partly dependent on material conditions. The very strong correlations of political trust with the two indicators of economic performance confirm the idea that political trust is highly responsive to the state of the economy.

It would be premature, however, to conclude that the economic crisis must have thus led to a drop in civic dispositions among young people as these dispositions may have been low at the onset in the countries most affected by the crisis. We therefore took the pre-crisis levels into account and examined whether changes in economic performance were correlated with changes in civic attitudes between 2008 and 2012 (see Table 3). The table shows the expected patterns for political trust: countries experiencing the sharpest rise in youth unemployment rates and the most dramatic contraction of the economy also witnessed the sharpest declines in political trust over the 2008-2012 period. Political trust is therefore highly dependent on both levels of and changes in economic conditions. Interestingly, deteriorating economic conditions did not have the same effect on civic dispositions. Apart from a weak negative impact on ethnic tolerance, they did not diminish levels of social trust and active civic 
participation. In other words, countries worst affected by the crisis have not experienced significantly sharper declines (or significantly lower increases) in trust and participation than countries least affected by the crisis.

In sum, while civic dispositions do not appear to be affected by changing economic conditions, they are dependent on the overall level of prosperity. How can this paradox be explained? Possibly, civic dispositions only start falling several years after the onset of an economic crisis. They may therefore not yet have declined in 2012, which is four years after the beginning of the most recent crisis and the latest year that we have survey data on. This would explain why we did not find a relation between changes in civic dispositions and depth of the economic contraction since 2008, while we did nonetheless find civic dispositions to be broadly dependent on material conditions. If this conjecture is true, civic dispositions should fall as the crisis continues.

Table 3: The link between changes in economic performance and changes in young people's civic attitudes and behaviours.

Change in youth unemployment Change in Aug 2008 - Aug 2012 GDP pc 2008-2012

\begin{tabular}{|l|l|l|l|l|}
\hline & Pearson's r & $N$ & Pearson's r & $N$ \\
\hline Changes in political trust 2008-2012 & $-0.74 * * *$ & 17 & $0.71^{* * *}$ & 16 \\
\hline Changes in social trust 2008-2012 & -0.20 & 17 & 0.30 & 16 \\
\hline Changes in tolerance 2008-2012 & $-0.41^{*}$ & 17 & $0.44^{*}$ & 16 \\
\hline Changes in active civic participation 2008- & 0.35 & 17 & 0.13 & 16 \\
\hline
\end{tabular}

$* p=0.1 ; * * p=0.05 ; * * * p=0.01$ 
Sources:

For the change in youth unemployment, see Eurostat (2015).

For the change in GDP pc, see Balcerowicz et al. (2013).

\section{Conclusion}

This article sought to investigate the impact of the recent recession on the civic dispositions of various age groups in western countries. It was hypothesized that the civic dispositions of young people might have been particularly affected as economic crises are usually disproportionately hitting the young. We found, however, that young people's civic dispositions have endured the recent years of economic adversity much better than their trust in political institutions. While young people's political trust responded immediately to the contraction by showing the greatest declines in countries most affected by the crisis, a similar pattern could not be observed for their civic dispositions, as changes in social trust and active civic participation were not related to changes in economic performance. Trend analyses confirmed this conclusion. Generally, trends in civic dispositions showed no connection with periods of economic contraction. Social trust, ethnic tolerance and post-materialist values actually rose during the most recent economic crisis in a country (Spain) and a group (the young) most severely afflicted by the crisis. Country-specific developments predominated, suggesting that civic culture is more dependent on local conditions.

At first sight this conclusion is reassuring. Apparently, civic culture is able to resist economic storms notwithstanding dramatic falls in public confidence in the institutions of government. Thus, the cultural foundations of democracy seem to be as solid as before, suggesting that democratic rule in western countries is stable and sound. However, we also found civic dispositions to be related to overall levels of economic prosperity and performance, 
indicating that such dispositions are not wholly immune to material conditions. Possibly civic culture is responding to economic contraction but only after some time. If true, we should see civic culture eroding in countries where the current crisis deepens such as in Greece and Italy. The next wave of the ESS and WVS should be able to give us more definite answers to this question. Our findings, in fact, closely correspond to those of Basora (2013), who found no evidence of democracy itself being affected by the crisis in most European countries. He speculated however, as we do, that a prolonged crisis may well undermine the public legitimacy of democracy, even in states with consolidated democracies.

The above conjecture also gives rise to the proposition that civic culture is more susceptible to enduring processes affecting people's life chances and well-being than to fleeting phenomena such as economic crises. Some of our trend data offer provisional support for this proposition. We saw that social trust already started declining among young people in Britain before the 2008 crisis. Similarly the two youngest cohorts in the United States witnessed quite a pronounced fall in post-materialist values from the early 2000s. In both countries the material conditions and opportunities of young people are under ever greater pressure due to the steady rise in the cost of housing and education and the growing levels of indebtedness, processes which started at the end of the 1990s. It might therefore be more productive to assess what such more enduring processes do to the cultural foundations of democracy than economic crises.

\section{References}

Almond, G. A. and Verba, S. (1963), The Civic Culture, Princeton: Princeton University Press.

APSA Task Force on Inequality and American Democracy (2004), 'American democracy in an age of rising inequality', Perspectives on Politics, 2:4, pp. 651-89. 
Balcerowicz, L., Rzo'nca, A., Kalina, L. and Łaszek, A. (2013), Economic Growth in the European Union, Brussels: Lisbon Council E-Book, http://www.lisboncouncil.net/growth/documents/LISBON_COUNCIL_Economic_Gr owth_in the EU\%20(1).pdf. Accessed 15 April 2015.

Basora, A. A. (2013), 'Can the post-communist democracies survive a continuation of the Euro-crisis', Orbis, 57:2, pp. 217-31.

Caviedes, A. A. (2010), Prying Open Fortress Europe: The Turn to Sectoral Labor Migration, Plymouth: Lexington Books.

Downs, W. M. (2012), Political Extremism in Democracy: Combating Intolerance, Basingstoke: Palgrave.

Esping Andersen, G. (1990), The Three Worlds of Welfare Capitalism, Princeton, NJ: Princeton University Press.

Eurostat (2013), 'Eurostat news release Euro indicators August 2013: Euro area unemployment $\begin{array}{llll}\text { rate } & \text { at } & 12.0 \%, & \text { at } 28\end{array}$ http://epp.eurostat.ec.europa.eu/cache/ITY_PUBLIC/3-01102013-AP/EN/301102013-AP-EN.PDF. Accessed 15 April 2015.

(2015), 'Online statistics', http://appsso.eurostat.ec.europa.eu/nui/show.do?dataset=une_rt_m\&lang=en. Accessed 16 April 2015. 
Finkel, Steven, Muller, Edward, and Seligson, Mitchell A. (1989), 'Economic crisis, incumbent performance and regime support: A comparison of longitudinal data from WestGermany and Costa Rica', British Journal of Political Science, 19: 3, pp. 329-51.

Fox, J. (2000), 'Civil society and political accountability: Propositions for discussion', paper presented at the Institutions, Accountability and Democratic Governance in Latin America Conference, South Bend: University of Notre Dame, 8-9 May.

Fukuyama, F. (1995), Trust: The Social Virtues and the Creation of Prosperity, London: Hamish Hamilton.

Galston, W. (1991), Liberal Purposes: Goods, Virtues, and Diversity in the Liberal State, Cambridge; New York: Cambridge University Press.

Gamson, W. A. (1968), Power and Discontent, Homewood, IL: Dorsey.

Giddens, A. (1991), Modernity and Self-Identity. Self and Society in the Late Modern Age, Cambridge: Polity.

Green, A. and Janmaat, J. G. (2011), Regimes of Social Cohesion: Societies and the Crisis of Globalization, Basingstoke: Palgrave Macmillan.

Horvath, A. and Paolini, G. (2013), 'Political participation and EU citizenship: Perceptions and behaviours of young people (evidence from the Eurobarometer surveys)', 
http://eacea.ec.europa.eu/youth/tools/documents/perception-behaviours.pdf. Accessed 17 April 2015.

Hoskins, B., Jesinghaus, J., Mascherini, M., Munda, G., Nardo, M., Saisana, M., van Nijlen, D., Vidoni, D. and Villalba, E. (2006), 'Measuring active citizenship in Europe', CRELL Research Paper 4. Ispra: European Commission.

Ibarra, E. (2011), 'Xenophobia in times of crisis', https://movementagainstintolerance.wordpress.com/2011/03/24/xenophobia-in-times-of-crisis/. Accessed 17 April 2015.

Inglehart, R. (1990), Culture Shift in Advanced Industrial Societies, Princeton: Princeton University Press.

Inglehart, R. and Welzel, C. (2005), Modernization, Cultural Change, and Democracy: The Human Development Sequence, Cambridge: Cambridge University Press.

Ishkanian, A. (2007), 'Democracy promotion and civil society', in Martin Albrow, Marlies Glasius, Helmut K. Anheier and Mary Kaldor (eds), Global Civil Society 2007/8: Communicative Power and Democracy, Global Civil Society - Year Books, London: Sage, pp. 58-85.

Klingemann, H. D. (1999), 'Mapping political support in the 1990s: A global analysis', in P. Norris (ed.), Critical Citizens: Global Support for Democratic Governance, Oxford: Oxford University Press, pp. 31-56. 
Knack, S. and Keefer, P. (1997), 'Does social capital have an economic pay-off? A crosscountry investigation', Quarterly Journal of Economics, CX11: 4, pp. 1251-88.

Kymlicka, W. (2002). Contemporary Political Philosophy: An Introduction. Oxford UP, Oxford.

Lichterman, P. (1996), The Search for Political Community: American Activists Reinventing Commitment, Cambridge: Cambridge University Press.

Lipset, S. M. (1959), 'Some social requisites of democracy, economic development and political legitimacy', American Political Science Review, 53: 1, pp. 69-105.

Maslow, A. H. (1943), 'A theory of human motivation', Psychological Review, 50:4, pp. 37096.

Newton, K. (1999), 'Social and political trust in established democracies', in P. Norris (ed.), Critical Citizens, Oxford: Oxford University Press, pp. 169-87.

Ostrom, E. (1990), Governing the Commons: The Evolution of Institutions for Collective Action, New York: Cambridge University Press.

Pilkington, H. and Pollock, G. (2015), “Politics are bollocks”: Youth, politics and activism in contemporary Europe', The Sociological Review, 63:S2, pp. 1-35.

Putnam, R. (1993), Making Democracy Work: Civic Traditions in Modern Italy, Princeton, NJ: Princeton University Press. 
Putnam, R. (2000). Bowling Alone: The Collapse and Revival of American Community. New York: Simon and Schuster.

Simsa, R. (2015), 'The social situation in Spain and the Spanish Protest Movement', ÖGfE Policy Brief 2. Vienna: ŐGfE.

Staręga-Piasek, J., Matela, P., Woyciska, I. and Piotrowski, B. (2006), 'Rescaling social welfare policies in Poland', National report for the European Centre for Social Welfare, Policy and Research (ECSWPR). Warsaw: ECSWPR.

Thomassen, J. J. A. (1990), 'Economic crisis, dissatisfaction, and protest', in M. K. Jennings and J. W. van Deth et al. (eds), Continuities in Political Action: A Longitudinal Study of Political Orientations in Three Western Democracies, Berlin and New York: de Gruyter, pp. 103-134.

Tocqueville, A. de (1969), Democracy in America (ed. J. P. Mayer), Garden City, NY: Anchor Books.

Uslaner, E. (2002), 'The moral foundations of trust', paper for the Symposium Trust in the Knowledge Society, University of Jyvaskyla, Jyvaskala, Finland, Department of Government and Politics, University of Maryland, 20 September.

Van Beek, U. and Vnuk-Lipinski, E. (2011), Democracy under Stress: The Global Crisis and Beyond, Stellenbosch: Sun Press. 
Wilkinson, R. and Pickett, K. (2009), The Spirit Level: Why More Equal Societies Almost Always Do Better, London: Allen Lane.

Williamson, H. (2014), 'Radicalisation to retreat: Responses of the young to austerity Europe', International Journal of Adolescence and Youth, 19:8, pp. 5-18.

World Bank (2005), 'GDP per capita, PPP (current international \$)', World Development Indicators Database, http://data.worldbank.org/indicator/NY.GDP.PCAP.PP.CD?order=wbapi_data_value_2013+wbapi_data_value+wbapi_data_valuelast\&sort=desc. Accessed 17 April 2015.

\section{Contributor details}

Jan Germen Janmaat is Reader in Comparative Social Science at UCL Institute of Education. His research focuses on the role of education, broadly conceived, in promoting civic values. He published in a great variety of journals from the fields of education, sociology and political science, including European Sociological Review, Ethnic and Racial Studies and Comparative Education Review.

Contact:

Department of Education, Practice and Society, UCL Institute of Education, 20 Bedford Way, London WC1H OAL, United Kingdom.

E-mail: g.janmaat@ioe.ac.uk

Notes 


\footnotetext{
${ }^{1}$ A table showing the number of respondents in each of the birth cohorts by survey, country and round can be obtained from the author upon request.

${ }^{2}$ These trends will be presented as a series of graphs, which enables a quick and easy determination of the main developments. The full statistics of the trends, including means, confidence intervals and significance levels can be obtained from the author upon request.

${ }^{3}$ This interpretation needs to be stated with caution due to the low numbers of respondents in the youngest cohort in the 1999-2004 round.

${ }^{4}$ The author will provide these results upon request.

${ }^{5}$ We measured political trust with an ESS item on confidence in parliament. The response categories of this item are (1) none at all, (2) not very much, (3) quite a lot and (4) a great deal.
} 